\title{
A Commentary on the Growth of the Human Brain and Skull '
}

\author{
MELVYN J, BAER AND JAMES E, HARRIS \\ Departments of Orthodontics and Oral Biology, The University of \\ Michigan, School of Dentistry, Ann Arbor, Michigan
}

\begin{abstract}
This paper tests the suggestion put forth by Tanner ('55) and Eichorn and Bayley ('62) to the effect that the brain participates in the parapubertal spurt of growth which characterizes many of the dimensions of the human body. To this end, longitudinal data consisting of oriented head roentgenograms of 11 boys were examined. Two measurements were taken directly from each lateral head film: (1) skull length, measured from glabella to opisthocranion, and (2) endocranial length, the maximum length of the endocranial contour in the mid-sagittal plane.

While many of the individual cumulative curves depicting growth in skull length exhibit a parapubertal acceleration, all of the curves for endocranial length comprise segments of a parabolic arc representing a single decelerating phase of growth. Mean incremental curves, mathematically fitted, further emphasize the differences in velocity and pattern of size attainment for the two dimensions tested. The data here presented, then, fail to implicate the brain in the general spurt of growth evident for the external dimensions of the head at adolescence.

It is suggested that two discrete systems are evident in the growth of the skull: a rapidly growing neural system essentially completed by adolescence, and a facial system of slower growth and longer duration. The conventional measurement of skull length cuts across both systems, appraising neural growth and the cerebral skeletal envelope prior to adolescence, and then superimposing the facial component, the forward projection of the frontal sinus, during adolescence and post-adolescence.
\end{abstract}

Since the publication of Scammon's ('30) curves of differential tissue growth (fig. 1), it has been generally accepted that the curve of brain growth does not exhibit the parapubertal acceleration which characterizes many of the dimensions of the human body. Scammon was of the opinion that the external dimensions of the head also adhered to the "neural" pattern of growth; nevertheless, subsequent studies by Goldstein (' 36 , '39), Shuttleworth ('39), Nanda ('55), Dokladal ('59), Eichorn and Bayley ('62), and Miklashevskaya ('66), among others, have demonstrated the presence of an adolescent spurt in head growth in American and European populations. Thus the dichotomy, equating the brain with the neural mode of growth and the external dimensions of the head with the somatic pattern, became established and reinforced.

Recently, however, Tanner ('55) and Eichorn and Bayley ('62) have challenged the conclusion that the brain does not participate in the adolescent acceleration. These authors have analyzed the incremental growth of head circumference in relation to the increases reported for scalp thickness (Young, '59a) and for the thickness of the bones of the cranial vault (Roche, '53; Young, '57) during the parapubertal period. They contend that the increases in the thickness of the bones and the surrounding soft tissues are insufficient to account for the magnitude of the increments observed for the external dimensions of the head; hence, the inference that accelerated brain growth must be a contributing factor.

Tanner and Eichorn and Bayley well recognize the tenuous nature of the evidence from which their inference is drawn. The best evidence would result from a direct longitudinal study of the brain itself, perhaps through the use of periodic pneumoencephalograms to reveal the surface area of the brain in two planes. Since this procedure is too drastic to warrant its application solely for research purposes, it is still necessary to resort to indirect evidence to ascertain the longitudinal pattern of hu-

1 This investigation was supported by Public Health Service Research grant DE 00221, from the National Institute of Dental Research, Bethesda, Maryland. 


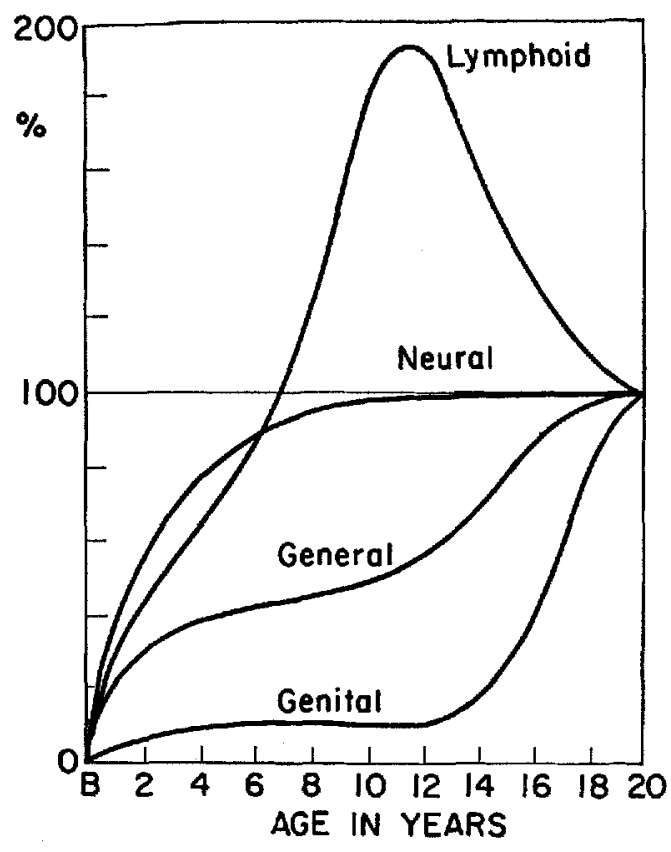

Fig. 1 Percentile curves of differential tissue growth (after Scammon, '30).

man brain growth. In this connection, data to be obtained from the endocranial surface of the skull represent a closer approximation to size changes in the brain than is to be obtained from external measurements of the head. Experimental investigations of the factors influencing the growth of the cranium indicate that the brain bears a functional relationship to the growth of the inner table of the vault bones (Washburn, '47; Massler and Schour, '51; Young, '59b; Moss and Young, '60). Logically then, measurement of the endocranial diameters of the vault ought to afford a reasonable approximation of changing brain size, conceding that some of the space is taken up by the membranous coverings and the cerebrospinal fluid.

In order to test the Tanner-Eichorn and Bayley hypothesis, therefore, longitudinal data consisting of oriented head roentgenograms taken on 11 boys were examined. Two measurements were taken directly from each lateral head film: (1) skull length, measured from glabella to opisthocranion, and (2) endocranial length, the maximum length of the endocranial contour in the mid-sagittal plane (fig. 2). The cumulative curves of growth for skull length and endocranial length for each of the 11 subjects are shown in figure $3 a, b$. The curves for each subject are numbered to facilitate a direct comparison of growth performance in the two diameters of the skull.

It is evident that the subjects with externally large skulls possess comparably large vaults endocranially. This fact is not surprising since the brain comprises the overwhelming content of the calvaria. Of greater significance for the present discussion, however, are the discernible differences in the slope and configuration of the two sets of curves. While the individual curves for skull length exhibit a steep slope and show increases well beyond 15 years

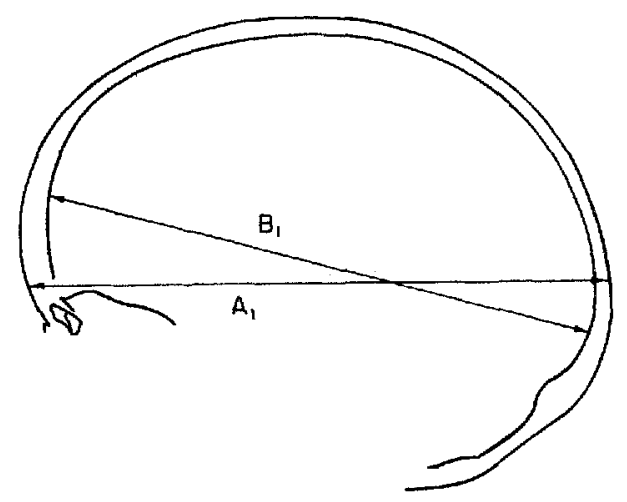

6 YEARS

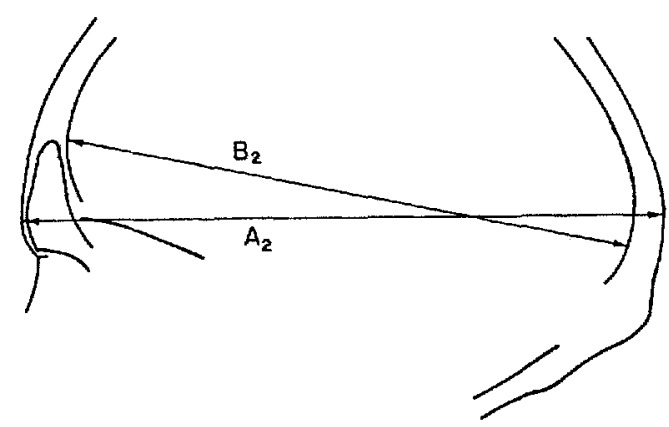

22 YEARS

Fig. 2 Lateral cephalometric tracings of $x$ rays taken on the same male subject at 6 and 22 years of age. $A_{1}$ and $A_{2}$ represent the maximum ectocranial length (glabella-opisthocranion) at each age; $B_{1}$ and $B_{2}$ represent the maximum endocranial length. 


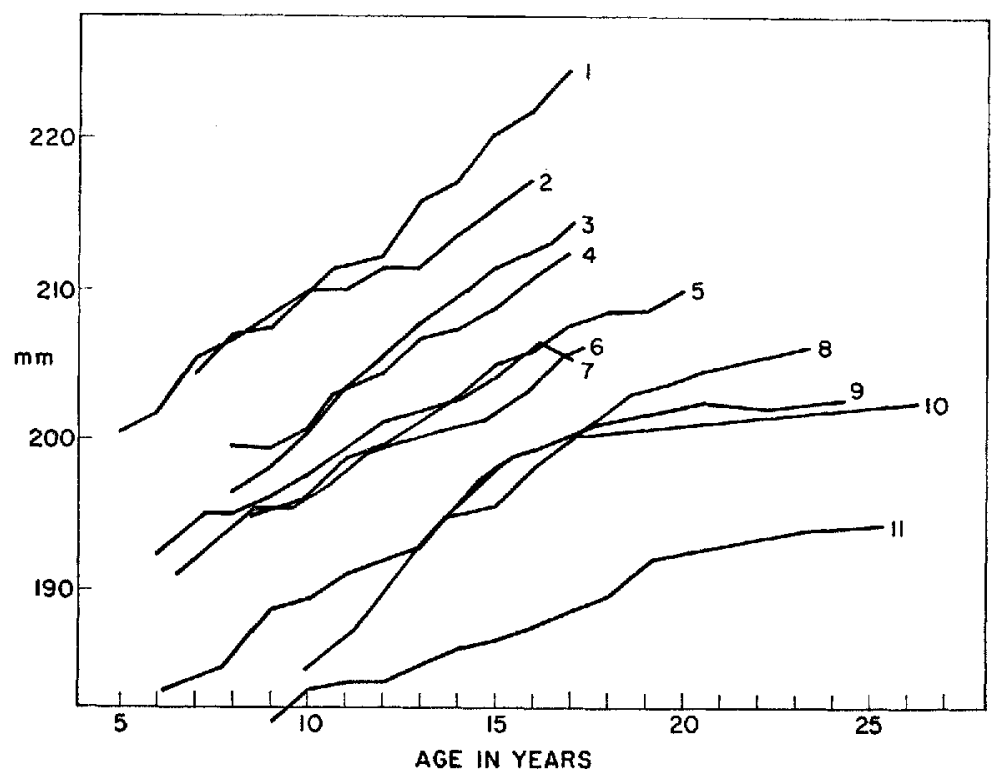

Fig. 3a Cumulative curves of growth for ectocranial length based on longitudinal data for 11 male subjects.

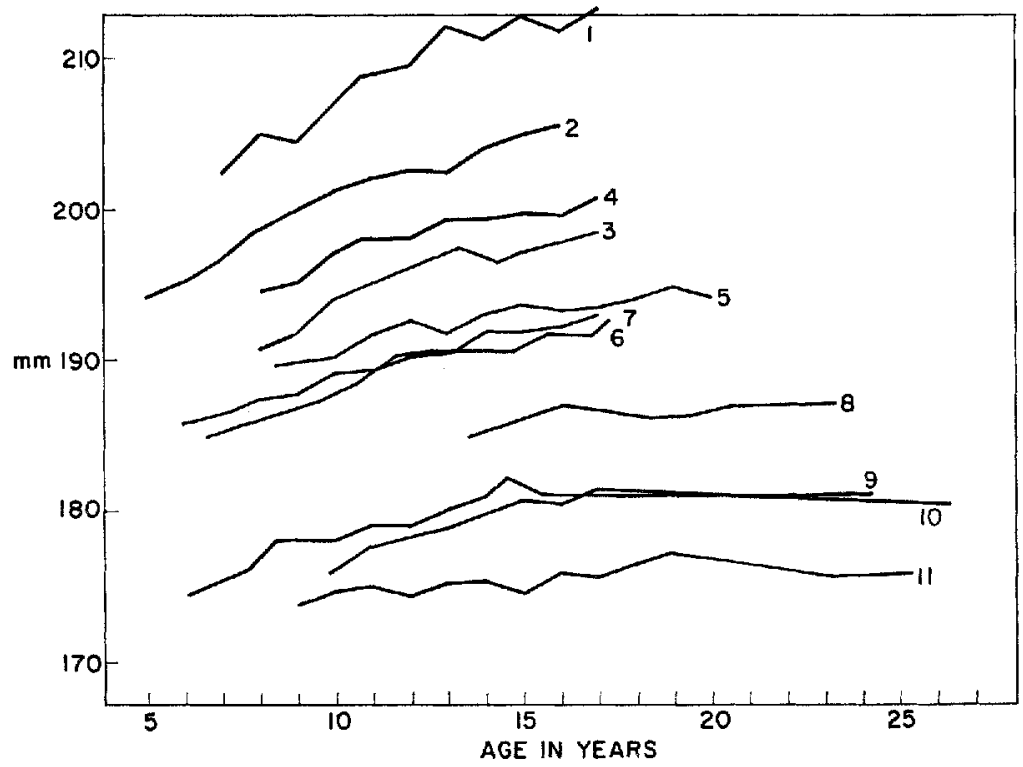

Fig. $3 \mathrm{~b}$ Cumulative curves of growth for endocranial length based on longitudinal data for 11 male subjects.

of age, the endocranial curves are relatively flat and tend to plateau around 15 years of age. While many of the curves depicting growth in skull length (subjects: $1,2,5,6,8,9,10)$ show at least a sugges- tion of a parapubertal acceleration, all of the curves for endocranial length comprise segments of a parabolic are representing a single decelerating phase of growth. 
As the term denotes, the cumulative curve adds the increment of gain at each successive time interval to the growth previously attained; consequently, this type of curve tends to mask small changes in rate of growth which might be taking place at adolescence. An averaging of the individual cumulative curves would further obscure the pattern of growth because the gross size differences of the subjects would increase the variance. Since it is the comparative rate of gain of ectocranial length versus endocranial length during adolescence which is the point at issue, the increments of growth at annual intervals were calculated for each dimension. Table 1 lists the mean gain, the standard deviation and the number of subjects for whom data were available at each chronological age. Data on at least ten subjects were obtained from ten through 17 years of age, the period critical for the present analysis. It is to be noted that the greatest differences occur from 12 through 16 years when the annual increments for external skull length exceed those for endocranial length by more than a millimeter. The peak difference $(1.34 \mathrm{~mm}$ ) occurs during the period from 14 to 15 years of age.
The mean incremental curves of growth for these two dimensions of the skull are clearly divergent in pattern (fig. 4). For external skull length, the increments are sustained through 16 years of age, after which time they exhibit a progressive decrease until roughly 22 or 23 years of age. For endocranial length, however, the increments decrease sharply after ten years of age. The slight increase indicated for the years 16-18 probably represents an artifact since it appears too late to be regarded as evidence of an adolescent acceleration. Further, it occurs at a time when the incremental growth of the external dimension is falling off rapidly and, therefore, it is unlikely that it would be reflected in an external measurement of the skull.

Curves fitted mathematically to the incremental data merely emphasize the differences in velocity and pattern of size attainment. Figure 5 shows the results of fitting curves to the mean increments using a quadratic equation. The curve for skull length is convex while that for endocranial length is concave. The greatest distance between the curves is found in the circumpubertal period.

The material here presented, then, fails to implicate the brain in the general spurt

TABLE 1

Annual growth increments ( $\mathrm{mm}$ )

\begin{tabular}{|c|c|c|c|c|c|c|}
\hline \multirow{2}{*}{ Age } & \multirow{2}{*}{$\underset{\text { size }}{\text { Sample }}$} & \multicolumn{2}{|c|}{ Skull length } & \multicolumn{2}{|c|}{ Endocranial length } & \multirow{2}{*}{$\begin{array}{c}\text { Difference } \\
\text { between } \\
\text { means } \\
(\mathrm{N} \equiv 10)\end{array}$} \\
\hline & & Mean & S.D. & Mean & S.D. & \\
\hline \multicolumn{7}{|l|}{ years } \\
\hline $5-6$ & 1 & 1.20 & 0.00 & 1.20 & 0.00 & \\
\hline $6-7$ & 3 & 1.72 & 1.75 & 1.04 & 0.37 & \\
\hline $7-8$ & 5 & 1.90 & 1.25 & 1.82 & 0.74 & \\
\hline $8-9$ & 7 & 1.27 & 0.85 & 0.44 & 0.58 & \\
\hline $9-10$ & 9 & 1.63 & 0.85 & 1.39 & 0.91 & \\
\hline $10-11$ & 10 & 1.85 & 1.01 & 1.09 & 0.58 & 0.76 \\
\hline $11-12$ & 10 & 1.42 & 0.88 & 0.53 & 0.61 & 0.89 \\
\hline $12-13$ & 10 & 1.75 & 1.10 & 0.71 & 0.94 & 1.04 \\
\hline $13-14$ & 10 & 1.50 & 0.74 & 0.48 & 0.85 & 1.02 \\
\hline $14-15$ & 11 & 1.76 & 0.92 & 0.42 & 0.58 & 1.34 \\
\hline $15-16$ & 11 & 1.57 & 0.46 & 0.31 & 0.79 & 1.26 \\
\hline $16-17$ & 10 & 1.30 & 1.14 & 0.54 & 0.66 & 0.76 \\
\hline $17-18$ & 6 & 1.00 & 0.54 & 0.50 & 0.78 & \\
\hline $18-19$ & 5 & 0.91 & 0.88 & 0.17 & 0.41 & \\
\hline $19-20$ & 5 & 0.70 & 0.47 & -0.05 & 0.22 & \\
\hline $20-21$ & 4 & 0.54 & 0.30 & 0.00 & 0.35 & \\
\hline $21-22$ & 4 & 0.30 & 0.23 & -0.08 & 0.20 & \\
\hline $22-23$ & 4 & 0.36 & 0.14 & -0.08 & 0.20 & \\
\hline $23-24$ & 3 & 0.24 & 0.00 & -0.16 & 0.18 & \\
\hline $24-25$ & 2 & 0.24 & 0.00 & -0.06 & 0.08 & \\
\hline $25-26$ & 1 & 0.24 & 0.00 & -0.12 & 0.00 & \\
\hline
\end{tabular}




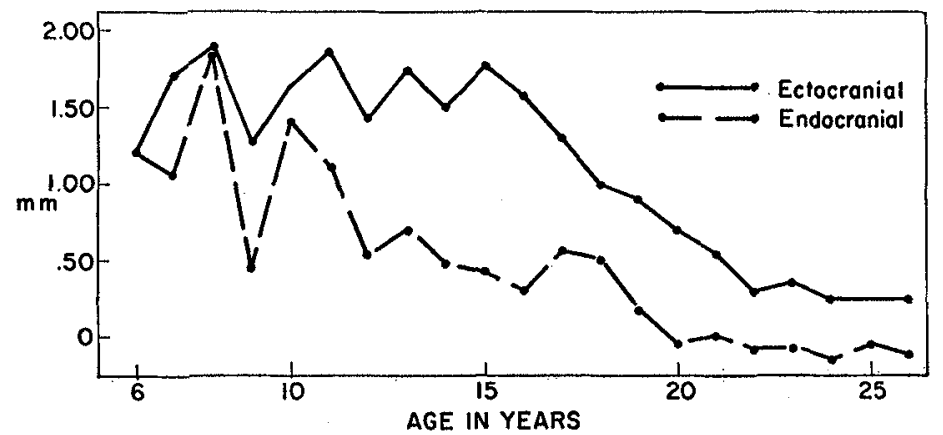

Fig. 4 Mean incremental curves of growth for ectocranial and endocranial lengths based on the 11 male subjects.

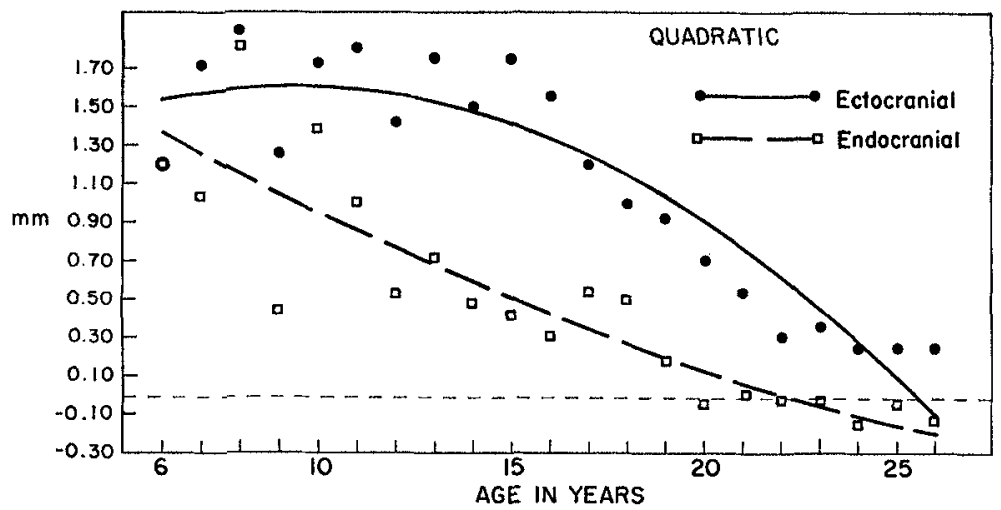

Fig. 5 Mathematically derived curves fitted to the incremental data for ectocranial and endocranial lengths using a quadratic equation.

of growth characterizing the external dimensions of the head at adolescence. But more broadly, the parameters tested support the contention that two discrete systems are evident in the growth of the skull: a rapidly growing neural system essentially completed by adolescence, and a facial system of slower growth and longer duration.

The glabellar area of the frontal bone has been shown to be a functional component of the facial skeleton (Moss and Young, '60). The development of the frontal sinus is a structural accommodation necessitated by the forward growth of the face. An anterior bulging of the outer cortical plate of the frontal bone takes place as an adjustive mechanism to maintain articulation of the frontal and nasal bones. This phenomenon is especially apparent in the male in whom the globular infantile forehead becomes receding after adolescence due to the development of a promi- nent glabellar area (fig. 2). Thus, the conventional measurement of skull length (GB-OP) cuts across both systems, assessing neural growth and the cerebral skeletal envelope prior to adolescence, and then superimposing the facial component, the forward projection of the frontal sinus, during adolescence and post-adolescence. The composite nature of the curve of growth for skull length is shown schematically in figure 6.

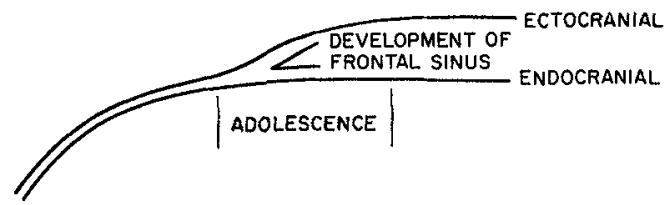

Fig. 6 Schematic diagram showing the composite character of the curve of growth for ectocranial length. The ectocranial curve incorporates neural growth, appositional growth of the cortical plates, and the development of the frontal sinus. 


\section{ACKNOWLEDGMENTS}

The writers are indebted to Dr. B. Holly Broadbent for his kind permission to study the cephalometric records of the Bolton Foundation and to Dr. Stuart J. Felhandler for his careful measurement of the tracings.

\section{LITERATURE CITED}

Dokladal, M. 1959 Growth of the main head dimensions from birth up to 20 years of age in Czechs. Hum. Biol., 31: 90-109.

Eichorn, D. H., and N. Bayley 1962 Growth in head circumference from birth through young adulthood. Child Develop,, 33: 257-271.

Goldstein, M. S. 1936 Changes in dimensions and form of the face and head with age. Am. J. Phys. Anthrop., 22: 37-89.

1939 Development of the head in the same individuals. Hum. Biol., 11: 197-219.

Massler, M., and I. Schour 1951 The growth pattern of the cranial vault in the albino rat as measured by vital staining with alizarine red "S." Anat. Rec., 110: 83-101.

Miklashevskaya, N. N. 1966 Growth of the head and face in boys of various ethnic groups in the USSR. Hum. Biol., 38: 231-250.

Moss, M. L., and R. W. Young 1960 A functional approach to craniology. Am. J. Phys. Anthrop., 18: 281-292.
Nanda, R. S. 1955 The rates of growth of several facial components measured from serial cephalometric roentgenograms. Am. J. Orthodont., 41: 658-673.

Roche, A. F. 1953 Increase in cranial thickness during growth. Hum. Biol, 25: 81-92.

Scammon, R. E. 1930 The measurement of the body in childhood. In: The Measurement of Man. By J. A. Harris, C. M. Jackson, D. G. Paterson and R. E. Scammon. University of Minnesota Press, Minneapolis.

Shuttleworth, F. K. 1939 The physical and mental growth of girls and boys age six to nineteen in relation to age at maximum growth. Monog. Soc. Res. Child Develop., 4: No. 3.

Tanner, J. M. 1955 Growth at Adolescence. Blackwell Scientific Publications, Oxford.

1962 Growth at Adolescence. 2nd ed Blackwell Scientific Publications, Oxford.

Washburn, S. L. 1947 The relation of the temporal muscle to the form of the skull. Anat. Rec., 99: 239-248.

Young, R. W. 1957 Postnatal growth of the frontal and parietal bones in white males. Am. J. Phys. Anthrop., 15: 267-386.

1959a Age changes in the thickness of the scalp in white males. Hum. Biol., 31: 7479.

$1959 \mathrm{~b}$ The influence of cranial contents on postnatal growth of the skull in the rat. Am. J. Anat., 105: 383-415. 